\title{
7. Media Advocacy for Public Health
}

\author{
Simon Chapman
}

This chapter describes two sets of insights about using the media to advocate for the health of the public. The first comes from my involvement in the campaign for plain packaging of cigarettes and other tobacco products. Second, I describe the results of a study examining the characteristics of influential Australian public health researchers, particularly their use of the media.

\section{Insights from the campaign to secure plain packaging of tobacco products}

On 1 December 2012 Australia became the first nation in the world to implement plain packaging of all tobacco products, after the legislation was supported by all three of Australia's main political parties. No country had ever mandated the entire appearance of packaging for any consumer product, so this historic legislation was at once exceptional, radical and a massive affront to the global transnational tobacco industry, which had for over 100 years packaged its products in highly consumer-tested boxes designed to maximise the appeal of both smoking and each brand.

How did this historic development happen?

The idea of requiring tobacco packs to be 'generic' or plain, with brands distinguished only by their names on the box in a standard font, was first suggested by a Canadian doctor from Vancouver, Gerry Karr, in 1986 (Lee 1986). After some advocacy for the concept in New Zealand, an unsuccessful attempt to see the idea implemented in the early 1990s in Canada, and some early testing of the likely impact in Australia, it went dormant for another decade as the powerful tobacco industry successfully framed the proposal as a fool's errand for any government to consider.

With tobacco advertising being rapidly eroded globally, the pack was coming into its own as the frontline of marketing and branding, as several researchers were pointing out (Slade 1997, Wakefield and Letcher 2002, Wakefield et al. 2002). In 2006, I commenced a National Health and Medical Research Council project grant examining the future of tobacco control. As part of this, in August 2007 we published an online review (Freeman et al. 2007) of the limited experimental evidence on the idea, together with insights into the 
importance of packaging, found in internal tobacco industry documents and the tobacco retail trade press. A peer-reviewed version subsequently published (Freeman et al. 2008) contained a detailed description of what plain packaging would need to embrace if it was to avoid subversion from an industry well practiced in that art from decades of evading advertising restrictions.

Working in public health research, where the whole idea is to produce work that is useful to informing public opinion and leveraging policy interest, I have never seen the sense in publishing work that is only read by a few hundred colleagues closeted behind journal subscriptions and paywalls. So I often push my research, distributing it to relevant people and writing journalistic pieces to accompany the publication of my scholarly papers.

I circulated the paper widely among my Australian colleagues and to some 5,000 members of a closed global internet listserv, GlobaLink. My sense was that the main objective at the time was to first reoxygenate the dormant concept among the global tobacco control community, to allow it to become part of the narrative of what was needed if nations were to get serious about continuing the reductions in smoking and in the many diseases it causes.

I did not, however, write my normal newspaper opinion page or online blog article to accompany the paper. I sensed that plain packaging was an issue that would first need considerable selling within the public health community, who would need to be comfortable enough with it to become enthusiastic supporters once it got out there as a policy being advocated for adoption. Being novel and never implemented before, it needed to be workshopped in preparation for the inevitable major attacks it would attract.

Over my career, I have spent interminable hours sitting on a large number of committees. Often these are inconsequential and deaden the spirit, but occasionally they can be catalysts to important outcomes. In 2008, I was appointed to the Tobacco Task Force of the Preventative (sic) Health Task Force, an initiative of the Commonwealth Department of Health and Ageing that had been established as a direct response to the newly elected Rudd Labor Government's explicit emphasis on the importance of prevention in health policy reform. With 50 or so others, I had been invited to a briefing by the new Health Minister, the Hon. Nicola Roxon. Her presentation commenced with and dwelt on prevention, not in its normal role as a policy confection to be sprinkled on the more dour real meat and potatoes of health policy such as hospitals and treatment services, but as a primary consideration. Here was a rare government sending direct and forceful signals that prevention was to be taken seriously. Roxon at once seemed one of us, inhabiting the same population-focused values as the public health community. 
On the first day the task force met, its chair, Mike Daube, emphasised that his brief had been to convene a committee of experts who should be in no doubt that the government wanted recommendations that would really make a difference. We took turns to propose sometimes bold but always evidence-based actions. An increased tobacco tax was unanimous, but the substantial size of the proposed increase we agreed on ( 25 per cent) reflected the spirit of the government's clear interest to take prevention seriously.

I predictably recommended plain packaging, which was again unanimously accepted by the committee. I recall remarks about 'we can be bold here ... it's important that we get it out there on the agenda, even though it will probably take years to get up'. That was the spirit of our recommendation. I doubt there was anyone in the room who expected that the proposal would have any life other than as a historic but merely 'noted' recommendation in a report.

The proposed legislation was first announced on 29 April 2010, at a press conference held by Prime Minister Kevin Rudd and his health minister, Nicola Roxon, although late night television broke the news the night before, after Roxon's office had called me and others at about 6 pm. Dr Angela Pratt, Roxon's chief of staff, told me deadpan, 'I thought you might like to know that we'll be announcing tomorrow that we'll be introducing plain packaging'. I could almost see her beaming down the phone. From that moment, those working in population-focused tobacco control in Australia did little else for the next two years than concentrate our efforts to ensure the announced bill would be passed.

\section{Policy reform}

The confluence of a newly elected government with a prevention reformist agenda; the presence in that government of a passionate, highly educated and articulate minister with accessible staff; the opening of a window of opportunity in the form of a task force charged with maximising policy impact; and a small, closely networked and highly experienced circle of policy entrepreneurs advocating for change, epitomise several of the key ingredients of John Kingdon's analysis of policy reform (Kingdon 2003). But these features were all proximal factors that leave unexplained how a radical idea like plain packaging, when landing on the desk of a new government, found such favour. Proximal factors such as those which Australian tobacco control enjoyed with plain packaging are doubtless necessary to such policies gaining traction, but they are hardly sufficient, as the long trail of policy detritus of excellent, evidence-based proposals that got nowhere should make obvious. It has long been banal to note that policy adoption is not simply a matter of presenting the best facts and evidence to policymakers and sitting back to watch evidence 
triumph over other considerations. With rare exceptions, policy entrepreneurs and advocates need to engage in serious, extended and highly strategic efforts to ensure that evidence is communicated in ways that make it publicly and politically compelling, so that inaction is not an option. Policy solutions need to be framed in ways that make their rejection problematic. 'Killer facts' (Bowen et al. 2009) need to be mined from eye-glazing data; memorable sound bites (averaging 7.2 seconds) (Chapman et al. 2009) constructed and rehearsed; analogies forged with other issues known to have widespread support; and instinctive understanding developed of the importance of subtext and values referencing in effective communication (Chapman 2007).

While the proposal for plain packaging was novel, the case for it rested on the same long-running narratives that had seen governments of all persuasions incrementally ban all forms of advertising and promotion, commencing with the TV and radio direct advertising in 1976. The 'can't be half pregnant' (Chapman 2004) imperative allowed Roxon and public health advocates to argue that with plain packaging, they were simply finishing the job of banning tobacco advertising because frank admissions by the industry were abundant that packaging was now the frontline of tobacco advertising in 'dark markets' like Australia (Chapman et al. 2003).

Dominant public discourses involving routine framings of the tobacco industry as nefarious, duplicitous, venal, being corporate Pied Pipers, purveyors of deadly products and being indifferent to the health of Australians (Christofides et al. 1999) have been current for at least 40 years. These have grown ever more heated as tobacco use and the industry promoting it become increasingly denormalised (Chapman and Freeman 2008) as smoking prevalence continues to fall. With only 15 per cent of Australians smoking today, and 90 per cent of smokers regretting ever having started (Fong et al. 2004), only 1.5 per cent of Australian adults are smokers who enjoy being smokers. And only a fraction of these are likely to be smokers who care enough to speak out against effective tobacco control measures. Many smokers in fact support tobacco control because they believe it might help them to stop. During the campaign to defend the bill, Roxon said repeatedly that she has never met a smoker who hoped their own children would grow up to become smokers.

Because of three decades of advocacy and incremental government action, smoking has become an issue with vanishingly few champions in Australia. Any political party seen to be going out of its way to support the tobacco industry's interests risked sending a message that would resonate with a very small proportion of the community. 
From the moment the government's intentions on plain packaging were announced, a series of major enabling goals became evident. These included ensuring that the research informing the design of the new packs would maximise the main goals of the policy: to make cigarette packs look as unappealing as possible, and to maximise the impact of the graphic health warnings. Legal expertise was also vital in preparing for the anticipated challenges in both Australian courts and internationally, in forums such as the World Trade Organization, and in drafting the legislation itself. The Health Department needed to steel itself for an obstructionist campaign involving massive requests from the tobacco industry under Freedom of Information, fishing for any document that might assist their efforts to derail the policy.

But one of the most important tasks was to ensure that the government's commitment to the legislation received widespread public and all-party political support, the latter being vital because the government held power only with support of minor parties and independent crossbenchers. It became quickly apparent that the bill was highly likely to pass even without the Opposition's support. But it was unanimously agreed that it would be important to gain Opposition commitment too, to ensure ongoing support not only for this bill, but for future tobacco control initiatives in the event of a subsequent change of government.

For this to have happened, and to understand why a proposal as radical as plain packaging was picked up politically and eventually supported by all political parties when the bill was voted on, it is necessary to understand the central place that media advocacy has had in the DNA of Australian tobacco control leadership.

\section{Using the media to meet the nation's most senior politicians}

I speak with many researchers who express frustration at the rare opportunities they get to meet with politicians and senior policymakers. I probably get to meet with politicians and senior policymakers only a few times each year myself, if that. But I tell colleagues and students that I 'meet' these people many times each month, often at times when they are most relaxed and receptive. I had never met Nicola Roxon until invited to her 2008 prevention forum. As we met, she said 'I feel I have known you most of my life', referring to my long involvement in news media. So while I had never previously had the opportunity to put proposals to her directly, it was immediately clear that I had done so on innumerable occasions as she awoke to radio news and commentary, in her car as she drove to work or around on weekends, via her newspapers, through television news and via any online feeds she may have followed. Her cabinet 
colleagues would also all need to be voracious news consumers, so when health portfolio items arose, they too would be acquainted with the public narratives about these issues that have been circulating in news media.

Many researchers today remain ambivalent about media engagement and some are 'deeply distrustful' (US House of Representatives Committee on Science 1998). The values implicit in Sir William Osler's 1905 advice that doctors should not 'dally with the Delilah of the press' (Osler 1905) remain alive today in academic research circles, particularly in disciplines 'where practitioner or liberal educational values counsel modesty and impartiality' (Orr 2010, 23) Concerns are sometimes muttered about the impropriety of researchers actively engaging with the media to publicise their research and, particularly, to advocate for policy — an activity said by some to politicise science (Weigold 2001).

Wilkes and Kravitz's study of first authors whose research had received press coverage found that, while most authors were satisfied with the coverage, a substantial minority thought that media attention 'gives the impression that the researcher is seeking publicity' and 'creates jealousy among colleagues' (Wilkes and Kravitz 1992). Such concerns were echoed in a major study undertaken for the Royal Society in which 20 per cent of British scientists believed colleagues who appeared in the media were 'less well regarded' by their peers - seen as selling out or seeking self-publicity. To this minority, public engagement was something 'light' or 'fluffy' and 'done by those who were "not good enough" for an academic career' (People Science \& Policy 2006, 11).

The potential pitfalls of media engagement are well documented, focusing on concerns about sensationalised framing and the misrepresentation inherent in reducing scientific and conceptual complexity to sound bites (Orr 2010, Parry 2002, Schwitzer et al. 2005). Consequently, the literature is full of instances of poor relations between researchers and journalists (Valenti 1999, Maille et al. 2010). For example, 60 per cent of British researchers want to engage with policymakers about their research, but far fewer want to talk to journalists (31 per cent) (People Science \& Policy 2006, 9), despite common knowledge that politicians are voracious consumers of news where they daily encounter expert and public opinion directly relevant to their portfolios.

Nevertheless, many researchers engage often and effectively with the media, believing media coverage of their work has significant benefits (Gascoigne and Metcalfe 1997, Gething 2003). Independent health experts are the sources most trusted by journalists covering health issues (Leask et al. 2010); experts are the second most frequent category of news actor in Australian television health news stories, after those experiencing health problems (Chapman et al. 2009). 
Yet many researchers remain ambivalent about media engagement, despite strong political encouragement to do so (Department of Innovation, Industry, Science and Research 2010).

Previous studies on how scientists communicate with the media have focused on understanding factors associated with this engagement, particularly challenges and barriers (Dunwoody and Ryan 1985, Peters 1995, Gascoigne and Metcalfe 1997, Poliakoff and Webb 2007, Besley and Nisbet 2011). These include confidence in talking to the media (Poliakoff and Webb 2007), the reaction of colleagues (Gascoigne and Metcalfe 1997), and concerns about the accuracy of reporting (Peters 1995). However, until we began our work examining leading public health researchers, there had been little research on why and how such researchers engage in public discussion of their research and policy and the strategies they use to overcome these barriers and challenges.

\section{Insights from leading 'influential' public health researchers $^{1}$}

In 2009-10, I worked with others on a project looking at the characteristics of influential Australian public health researchers (Chapman et al. 2014, Haynes et al. 2011a, 2011b, 2012). We interviewed 36 researchers who had been voted as the six most influential researchers in six fields of public health (alcohol, illicit drugs, injury prevention, obesity, skin cancer prevention and tobacco control). In interviews lasting 60-90 minutes, we asked them to try and reflect on why they believed they had been thus ranked by their research peers. We also interviewed senior policymakers (politicians, their staff, senior bureaucrats) and asked them to reflect on how they came to learn about public health expertise, to use and trust such experts and to regard them as influential.

Three-quarters of Australian politicians we interviewed on how politicians identify expertise placed great importance on media profile, with media presence sometimes disturbingly considered as commensurate with expertise: 'the media is used as a proxy for being an expert in the area'. For one political adviser, it was the only means of identifying experts: 'I have absolutely no idea how I would go about identifying someone if there wasn't an obvious expert prominent in the media' (Haynes et al. 2012).

1 The unattributed quotations in this section come from interviews with leading influential public health researchers. They are unattributed to protect confidentiality. See also Chapman et al. 2014, Haynes et al. 2011a, 2011b, 2012. 


\section{Perceptions of the media}

Our informants considered news media to be both peerless in their power to influence, and a potentially problematic but vital channel for researchers who wished to advance research-informed policy. The sheer reach of media surpassed any academic forum for research dissemination:

I spoke on [a radio program] last night for example, and there probably would have been, at minimum, 100,000 people listening to that, which is an audience that you would never dream of speaking to in a scientific conference.

Television was seen by some as the most powerful medium:

If you want to see change, the television screen is really the way to do it. The television screen of the mid-twentieth century has changed more health policy than the Gutenberg revolution of the mid-fourteenth century has or ever will.

The ability of the media to affect policy agenda-setting was of paramount interest to most researchers. Media coverage of health issues had 'brought the community along' with new ways of thinking about public health: 'Without ... the softening up that the media did, it [tobacco control legislation] would not have been as acceptable as it ultimately was to the community.' This critical mass of public interest and support could then provide the catalyst for policymakers to back proposals:

Doing things that will attract media attention and getting good media coverage is another way of getting policy into action indirectly by preparing the community for things or creating a demand in the community that then starts to be felt politically which ultimately leads then through to action in the political sphere as well as more widely in the community.

The major concern of researchers was about possible misrepresentation caused by the media's insistence on simplification resulting in inadequate contextualisation of data or commentary; because of lazy and factually incorrect reporting; or media spin (deliberate efforts to selectively frame the meaning of research, often for sensationalist purposes).

A clear majority ( 86 per cent) agreed that public health researchers have a duty to increase public awareness of their work and the same percentage agreed that public health researchers had a duty to influence policy and practice. 
Media engagement was seen as integral and vital here: 'If you're trying to influence policy, which is really what we were trying to do, we had to put information into the public arena.'

Some interviewees had encountered colleagues who questioned the motivation of media-engaged researchers, seeing their promotion of research as an unseemly, 'ego-driven, empire-building' activity.

These critical colleagues dismissed those who engaged with the media as 'self-promoting' or 'show ponies', terms 'designed to circulate the view that proper science is science which does not seek to promote or publicise its findings'.

\section{Strategies used by influential researchers}

All but one of our interviewees regularly engaged with the media because of the 'huge advantage' it provides in 'getting your research out there'. In many cases, this had led to an advantageous media profile that, once established, became almost self-perpetuating with the media returning regularly and the researcher gaining further opportunities to promote research: "They see that you can articulate an issue and so you tend to get called and that kind of snowballs into becoming the "go to" person.'

Establishing this relationship was seen to be dependent on several attributes: managing simplification, framing, having an opinion, being available and institutional capacity and support.

\section{Managing simplification}

Given that the average duration of comments on Australian television news is 7.2 seconds (Chapman et al. 2009), being 'media-friendly' meant 'being able to collapse your complex important findings into the briefest sound bites' and 'knowing what to pick. What is it out of your research that the media is actually going to be interested in?'

The measured and qualified language of science was seen as having little place in media commentary:

The media's not interested in people who say on the one hand and on the other hand and on the third hand and on the fourth hand. Academics might be interested in that sort of nonsense but no one else is.

The challenge was for researchers to find ways of truncating research, while maintaining its integrity. 
Several also noted the importance of modern information technology in providing research detail that the media so often omitted: 'The advent of the web has made it a lot easier to live with simplification in the media and then put all the complexity on the web.'

\section{Framing}

Using sound bites effectively not only provided the simplification that media coverage required, it also helped to frame key research findings and implications (Entman 1993, Lakoff 2004), rather than allowing journalists to decide which points were most salient and how they should be presented. Researchers who were able to find accessible but accurate ways of conveying research findings were regarded as highly successful and influential media operators:

He can spin things really well. I don't mean that in a negative way-he is somebody who has the most fantastic media style, is across the issues ... explains the issues endlessly to the media, to the general public and to the bureaucrats in ways that people can readily understand.

\section{Having an opinion}

Some interviewees had encountered colleagues who believed researchers should just 'stick to the facts' in interviews. This position was echoed by just two researchers who agreed that '[i]t is not appropriate for me to express my opinions about public health policy'. They argued that extrapolating policy implications from data was outside a researcher's remit: 'I think my public face while I am wearing a researcher's hat is to provide the data and to ensure that the data that are being discussed are the right data and are accurate.' However, the overwhelming majority (94 per cent) disagreed, arguing that the public expects experts to go beyond reciting and clarifying facts to provide commentary, to 'translate' data and explain its meaning for policy: 'They want to see what professor so and so says about it' because 'people always want to know what the policy implications are'.

While nearly everyone would consider it appropriate for experts to appear in news media to explain the facts, journalists and the public expect that experts should also have views worth hearing about what should be done. This is particularly so in public health, where much news is problem-focused. Discussions about problems invariably move from descriptions of the problem, to a focus on those responsible for the problem and its solution (Iyengar 1994). Any public health expert who tried to avoid discussion of such solutions would rapidly find themselves marginalised as an authority. The public would reason, 'What sort of an expert is this, who knows so much about the problem but doesn't seem to have any views about what should be done to fix it?' 


\section{Being available}

All but one of our interviewees regarded 'being available' to the media as being a component of their professional role. Consequently, these researchers all agreed with the statement that 'I generally respond to media requests to promote awareness of my research', thus being 'assiduous in courting the media and being available at reasonable and unreasonable times when they contact you'.

Some had come to know journalists personally and often assisted them behind the scenes. Several spoke of the symbiosis between the need of researchers to gain public and political attention for their issues and the need of journalists for reliable and credible sources to help them provide authoritative stories. This occasionally led to openings for researchers to suggest stories: 'There were a few journalists who had me on their books and if it was a quiet news day they'd give me a call.'

\section{Institutional capacity and support}

Researchers were divided on academic institutional support for researchrelated media engagement. Many pointed to the lack of encouragement inherent in traditional academia which focuses on 'teaching and research rather than service to the community or being a public intellectual':

None of this gets counted in an academic's workload or output. It is something that individual senior researchers, in Australia at least, have tended to take on for themselves because they are passionate about public health. Not because they get paid for it.

But others remarked that this neglect was fading fast, with universities highlighting and rewarding their media-active staff and requiring researchers to keep records of media appearances for institutional profiles:

The sort of mentality that I'm talking about ... 'Don't do anything to publicise your research', it's almost evolving away from that in leading research universities ... They encourage their staff to engage with the community and with policymakers.

This attitude had evolved to such an extent in some universities that some of the most media-engaged researchers were promoted as peer role models: 'If you go to the faculty website ... there is a page where it says "featured academics". I am one of them. I am probably featured because others understand that I embody that approach to my research and that's acknowledged within the faculty as something that they wish to encourage.' 


\section{Discussion}

While almost all of the peer-rated influential researchers we interviewed recognised the importance of media engagement, they were also sensitive to concerns about its inherent constraints, the dilemmas posed by differences between journalistic and academic cultures and the reputational risks from an injudicious embrace of media celebrity. The major concerns were the news media's insistence on brevity and simplification, and the resultant dumbing down of complexity, and intolerance of inconclusiveness in encapsulating commentary within sound bites. This group of researchers appeared to have developed strategies to overcome these constraints, such as interacting with media workers that they knew and trusted. To most, these concerns were offset by the judgment that to absent oneself from the media was to almost guarantee the irrelevance of one's research to public and political debates about health policy.

Overall, the opportunity that media engagement provided for researchers to contribute to research-informed public awareness and debate was regarded not only as appropriate by most of our influential interviewees, but as a critical aspect of their professional duty to advance public health. It seems these researchers recognise that the nature of media coverage is shaped, in part, by those who initiate stories, meaning that researchers can not only generate media interest in public health research and research-informed policy, but can also set in motion the framing of such stories and influence their effect on public health policy.

In conclusion, this study showed that a willingness and capacity to engage with mass media was seen as an essential attribute of influential public health researchers by most influential Australian researchers. Most of these researchers were comfortable in performing this role and made themselves available to the media to comment on their own research and that of others in their field, and on matters of public health policy relevant to their expertise. This was done with awareness of the limitations of the media and of the difficult path that must be followed in making policy recommendations without being seen as a policy advocate who ventures beyond the evidence or selects evidence to advance a particular policy agenda. 


\section{References}

Besley, J and Nisbet, M (2011) How scientists view the public, the media and the political process. Public Understanding of Science doi:10.1177/0963662511418743. Epub 30/8/2011.

Bowen, S, Zwi, A and Whitehead, M (2009) Killer facts, politics and other influences: what evidence triggered early childhood intervention in Australia? Evidence and Policy 5(1): 5-32.

Chapman, S (2004) 'Half-pregnant': occupational health policy on environmental tobacco smoke. Occupational and Environmental Medicine 61(5): 383-4. Epub 20/4/2004.

Chapman, S (2007) Public health advocacy and tobacco control: making smoking history. Blackwell, Oxford.

Chapman, S and Freeman B (2008) Markers of the denormalisation of smoking and the tobacco industry. Tobacco Control 17(1): 25-31. Epub 26/1/2008.

Chapman, S, Byrne, F and Carter SM (2003) 'Australia is one of the darkest markets in the world': the global importance of Australian tobacco control. Tobacco Control 12 Suppl 3:iii: 1-3. Epub 3/12/2003.

Chapman, S, Haynes, A, Derrick, G, Sturk, H, Hall, WS and St George, A (2014) Reaching 'an audience that you would never dream of speaking to': influential public health researchers' views on the role of news media in influencing policy and public understanding. Journal of Health Communication 19(2): 260-73.

Chapman, S, Holding, SJ, Ellerm, J, Heenan, RC, Fogarty, AS, Imison, M, MacKenzie, R and McGeechan, K (2009) The content and structure of Australian television reportage on health and medicine, 2005-2009: parameters to guide health workers. Medical Journal of Australia 191(11-12): 620-4. Epub 24/12/2009.

Christofides, N, Chapman, S and Dominello, A (1999) The new pariahs: discourse on the tobacco industry in the Sydney press, 1993-97. Australian and New Zealand Journal of Public Health 23(3): 233-9. Epub 1/7/1999.

Department of Innovation, Industry, Science and Research (2010) Inspiring Australia: a national strategy for engagement with the sciences. Report to the Minister for Innovation, Industry, Science and Research. Commonwealth of Australia, Canberra, available from www.innovation.gov.au/General/CorpMC/Documents/InspiringAustraliaReport.pdf. 
Dunwoody, S and Ryan M (1985) Scientific barriers to the popularization of science in the mass media. Journal of Communications 35(1): 26-42.

Entman, RM (1993) Framing: towards clarification of a fractured paradigm. Journal of Communications 43(4): 51-8.

Fong, GT, Hammond, D, Laux, FL, Zanna, MP, Cummings, KM, Borland, R and Ross, $\mathrm{H}$ (2004) The near-universal experience of regret among smokers in four countries: findings from the international tobacco control policy evaluation survey. Nicotine \& Tobacco Research 6 Suppl 3:S341-51. Epub 1/4/20051.

Freeman, B, Chapman, S and Rimmer, M (2007) The case for the plain packaging of cigarettes. Aug 1 [cited 2013 Mar 20], available from papers.ssrn.com/sol3/ papers.cfm?abstract_id=1004646.

Freeman, B, Chapman, S and Rimmer, M (2008) The case for the plain packaging of tobacco products. Addiction 103(4): 580-90. Epub 15/3/2008.

Gascoigne, $\mathrm{T}$ and Metcalfe, $\mathrm{J}$ (1997) Incentives and impediments to scientists communicating through the media. Science Communication 18(3): 265-82.

Gething, L (2003) 'Them and us': scientists and the media-attitudes and experiences. South African Medical Journal 93(3): 197-201.

Haynes, A, Derrick, G, Chapman, S, Gillespie, J, Redman, S, Hall, W and Sturk, H (2011a) Galvanisers, guides, champions and shields: the many ways that policymakers use public health researchers. Milbank Quarterly 89: 564-98.

Haynes, AS, Derrick, GE, Chapman, S, Redman, S, Hall, WD, Gillespie, J and Sturk, H (2011b) From 'our world' to the 'real world': exploring the views and behaviour of policy-influential Australian public health researchers. Social Science \& Medicine 72(7): 1047-55.

Haynes, AS, Derrick, GE, Redman, S, Hall, WD, Gillespie, JA, Chapman, S and Sturk, S (2012) Identifying trustworthy experts: how do policymakers find and assess public health researchers worth consulting or collaborating with? PLoS ONE 7(3): e32665. Epub 10/3/2012.

Iyengar, S (1994) Is anyone responsible? How television frames political issues. University of Chicago Press, Chicago.

Kingdon, J (2003) Agendas, alternatives, and public policies, 2nd ed. Longman, New York.

Lakoff, G (2004) Don't think of an elephant!: know your values and frame the debate - the essential guide for progressives. Chelsea Green Publishing, White River Junction, Vermont. 
Leask, J, Hooker, C and King, C (2010) Media coverage of health issues and how to work more effectively with journalists: a qualitative study. BMC Public Health 10(1): 535.

Lee, B (1986) Sell tobacco in no-frills wrappers, urge doctors. The Journal 1 October.

Maille, M, Saint-Charles, J and Lucotte, M (2010) The gap between scientists and journalists: the case of mercury science in Quebec. Public Understanding of Science 19: 70-9.

Orr, G (2010) Academics and the media in Australia. Australian Universities Review 52: 23-31.

Osler, W (1905) Aequanimitas with other addresses: internal medicine as a vocation. P Blakiston Son \& Co, Philadelphia.

Parry, V (2002) Scientists as communicators: how to win friends and influence people. Journal of Molecular Biology 319(4): 973-8.

People Science \& Policy (2006) Factors affecting science communication. Report for the Royal Society, Research Councils UK, and Wellcome Society. London, available from www.peoplescienceandpolicy.com/downloads/Science_ communication_quantitative_report_NAV.pdf.

Peters, H (1995) The interaction of journalists and scientific experts: cooperation and conflict between two professional cultures. Media, Culture \& Society 17(1): 31-48.

Poliakoff, E and Webb, T (2007) What factors predict scientists' intentions to participate in public engagement of science activities? Science Communication 29(2): 242-63.

Schwitzer, G, Mudur, G, Henry, D, Wilson, A, Goozner, M, Simbra, M, Sweet, M and Baverstock, KA (2005) What are the roles and responsibilities of the media in disseminating health information? PLoS Medicine 2(7): e215.

Slade, J (1997) The pack as advertisement. Tobacco Control 6(3):169-70. Epub 1997/12/13.

US House of Representatives Committee on Science (1998) Senate committee hearing: National science policy study part VI: Communicating science and engineering in a sound-bite world. Washington, DC, available from commdocs.house.gov/committees/science/hsy 134000.000/hsy134000_0f. htm. 
Change!

Valenti, J (1999) How well do scientists communicate to media? Science Communication 21: 172-8.

Wakefield, M and Letcher, T (2002) My pack is cuter than your pack. Tobacco Control 11(2):154-6. Epub 30/5/2002.

Wakefield, M, Morley, C, Horan, JK and Cummings, KM (2002) The cigarette pack as image: new evidence from tobacco industry documents. Tobacco Control 11 Suppl 1: I73-80. Epub 15/3/2002.

Weigold, M (2001) Communicating science: a review of the literature. Science Communication 23: 164-90.

Wilkes, MS and Kravitz, RL (1992) Medical researchers and the media: attitudes toward public dissemination of research. JAMA 268(8): 999-1003. Epub 26/8/1992. 
This text is taken from Change! Combining Analytic Approaches with Street Wisdom, edited by Gabriele Bammer, published 2015 by ANU Press, The Australian National University, Canberra, Australia. 